\title{
Expert system in medicine and its application at pulmonary diseases
}

\author{
Evren Bursuk $^{1}$, Sabriye Demirci ${ }^{2}$, Mehmet Ali Korpinar ${ }^{3}$,
}

\begin{abstract}
Objective: Our aim is to develop a medical expert system for pulmonary diseases providing practitioners and medical students with the advantages of improving their ability, minimizing the error and cost in diagnosing and developing their medical knowledge.
\end{abstract}

Material and Methods: CLIPS has been chosen as a programming environment for this study. A respiratory disease binary decision tree which helps us to create the system database which includes twenty-eight diseases is formed for the inference engine of this program.

Results: The evaluation of this program is based on hundred and eighty-nine patients' data each is classified into three data types. These are patient's history and physical findings, radiological data and laboratory data. The combination of them shapes four different data sets for each patient. The diagnosing result for each data set of each patient is compared with diagnosing of gold standards. If both results indicates the same disease this operation of the program is assumed as "accurate", otherwise as "error". These operations for the considered each data set are repeated for all patients' data. The total number of accurate diagnosis is divided by the number of all patients and these accuracy rates are respectively $64.02 \%, 71.43 \%, 82.54 \%$ and $96.83 \%$.

Conclusion: We can conclude that the accuracy of the system is enhanced with the increasing total number and type of data for each patient. Finally, further improvement on the performance and accuracy of the system may be obtained by designing the program with the self-learning ability.

Keywords: Expert system; Pulmonary diseases; artificial intelligence; Health

\section{Introduction}

The expert system which is a branch of artificial intelligence, was defined first time by Prof Edward Feigenbaum who has assumed to be pioneer in this subject, as "an intelligent computer program that uses knowledge and inference procedures to solve problems that are difficult enough to require significant human expertise for the solution" (1-3). Although the first examples of expert systems packaged softwares appeared in the middle of 1960s such as Dendral (1965), Hearsay (1971), etc, in fact the works on this subject started with the study in "post production rules" by McCulloch and Pitts in early 1940 s $(1,3)$.

On the other hand, the use of computers in medical decision making began in the early 1960s' with the implementation of programs focusing on the diagnosis part of the consultation. One of the first packages in medicine was MYCIN, developed by Dr. Edward H. Shortliffe in early 1970s. Since then, medical application areas of expert systems have been broadened covering most of its areas, especially the use of reasoning process in decision making with the self-learning ability has improved the reliability and accuracy of the programs such as expert systems for general practice or diabetes mellitus or hematology or prescription or schizophrenic disorders or eye diseases or endocrine disorders or laboratory medicine so on (4- 20)

In medicine, the reasoning process consists of four major components. These are : cue acquisition, hypothesis generation, cue interpretation, and hypothesis evaluation. The cue acquisition includes patients' history (symptoms, present and past medical history), clinical and laboratory data (findings) or psychological tests. The hypothesis generation is probable alternative hypotheses which are retrieved from the physician's memory. The cue interpretation is the component in which the data are considered in view of their contribution to the alternative hypotheses. Hypothesis evaluation is the main stage of reasoning process, in which the data are weighted and combined to determine until one of the diagnostic hypotheses already generated can be confirmed. 
If not, the problem must be recycled, new hypotheses should be generated and additional data should be collected until the verification is achieved (1, 21-23). In general, an expert system should have the characteristics of high performance, sufficient and quick response time, reliability, comprehensibility and flexibility. Although these systems in medicine have some limitations such as communicating difficulties with patients, differences in evaluation of patients' data and its acceptability by physicians and patients, they have undeniable advantages of minimizing the cost, having accessible permanent knowledge, improving reliability and accuracy of diagnoses, minimizing human errors and solving complex problems in medicine efficiently $(18,20,23-25)$.

The aim of this work is to develop a medical expert system for pulmonary diseases providing practitioners and medical students with the advantages of developing their ability, minimizing the error and cost in diagnosing and broadening their medical knowledge.

\section{Materials and Methods}

An expert system generally consists of user interface, explanation facility, working memory, inference engine, agenda, knowledge acquisition facility and knowledge base. As the meaning of user interface indicates that its function is to maintain communication between the user and the system. The explanation facility provides the user the necessary knowledge to understand and the ability to monitor the system's operation. The working memory is a collected database consisting of facts used by the system to decide which of the rules is able to be executed. The inference engine is said to be the brain of the expert system that reasons and determines which rules are satisfied by the facts and gives the priority to the satisfied one to be executed. The agenda is a list of satisfied rules produced by the inference engine for execution. The knowledge acquisition facility is an optional part of the expert system that provides ability for self-learning and capability for the user to enter knowledge into the system without coding. The knowledge base is the store for the factual and heuristic knowledge. The factual knowledge is the knowledge obtained from the human experts and the literature. On the other hand, the heuristic knowledge is mostly individualistic judgmental knowledge which is based on wide experience, good practice, proper judgment, smart guessing etc $(1,3)$.

In the knowledge base the knowledge is not just stored, it is also represented by means of formalization and organization. Although in practice there are several types of representation techniques, the most common technique is the production rule which comprises IF and THEN parts. Since the IF part lists a set of conditions in some logical combinations and in the THEN part its problem solving action is taken, these two parts also called a condition and an action. In expert systems, if the knowledge is represented as a series (chaining) of production rules, they are called rule-based expert system (3).

In a rule-based system, if the facts satisfy the IF part of the rules the inference engine generates the priority list. In this sort of inferencing, two general problemsolving methods are widely preferred. These are forward chaining and backward chaining. In the forward chaining, the chaining starts from a set of conditions (inputs) and moves toward some conclusion whereas in the backward chaining the conclusion (outputs) is known but a path to conclusion is not known, therefore the backward reasoning is needed.

In order to obtain a favorable outcome at the final stage of an expert system, the choice of suitable programming language is very important. Since the CLIPS (C Language Integrated Production System) originally created for the construction of the rulebased (and/or object-based) expert systems in 1985 at NASA and is still one of the easily available programming environment widely used in governal and public applications, it is one of program languages used in developing medical expert systems. Although the CLIPS limited to use the forward chaining problem solving method only, its use provides the designer following advantages: high portability, low cost, easy integration with external systems, extensibility, interactive development, validation and availability of full documentation. So, CLIPS is preferred as the programming language in this study as well. $(3,14-16,19,26)$.

As mentioned earlier, since the objective of this study is to develop a rule-based expert system for diagnosis of any disease related to the human respiratory system and the answers in inferencing in this problem are binary (yes and no), therefore it should be started with creating the knowledge base using a disease decision tree which may be easily constructed and translated into the production rules. Since the disease decision tree which we have created for this work is so large, its only small and translated part are given in Figure 1 and Figure 2, respectively.

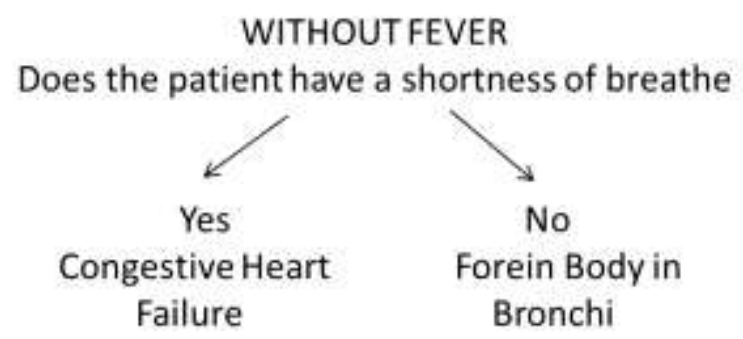

Figure 1: An example of disease tree. 


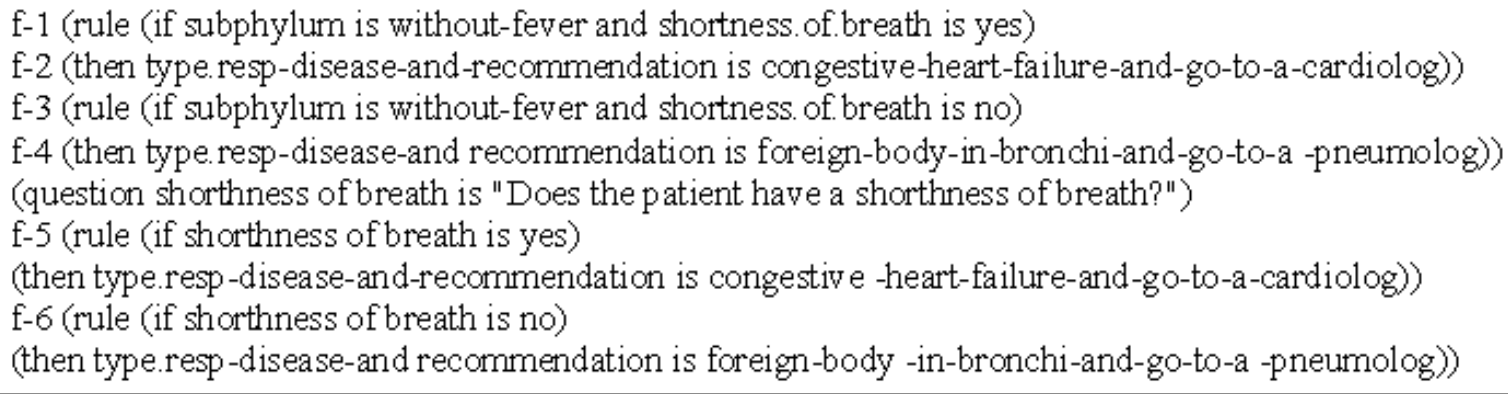

Figure 2: An example of representation by facts and rules .

The final nodes of the decision tree will give the below one of twenty-eight diseases and two statements which are elicited from the expert working in the university on respiratory diseases, medical reference books and the articles (27-33). The diseases considered in this study are upper respiratory viral infection, sinusitis, atypical pneumonia, typical bacterial pneumonia, tuberculosis, lung abscess, foreign body bronchi, bronchial asthma, chronic obstructive pulmonary disease - emphysema, chronic obstructive pulmonary disease - chronic bronchitis, bronchiectasis, cystic fibrosis, pulmonary embolism, pneumothorax, interstitial lung disease, bronchial adenoma, bronchial carcinoma, bronchorrea, postnasal drip syndrome, gastro-esophageal reflux, constructive pericarditis, congestive heart failure, right ventricular heart failure, pulmonary hypertension, cardiac tamponade, angina pectoris, acute myocardial infarction and Reynaud disease, and the statements which are grouped under the name of "other causes" advise the patients for whom not generated diagnosis by the system, to go to "a pneumologist" or "a cardiologist". The list of diseases and statements are represented as the production rules and facts in the knowledge base where the patient knowledge regarding the current statue of the patient is represented by facts only which form the working memory.

Meantime, the priority list is produced on the agenda by the inference engine.

As an example for this work, the diagnosis operation steps of one of the patients are given in Figure 3.

Results

As we have not mentioned yet, an important issue of the medical expert system is how to evaluate it.
.Wyatt who is assumed to be a pioneer on this subject suggested three fundamental measures; structure, performance and impact. The structure means that the construction of the system which required quality depends on the machine-readable store of right knowledge represented appropriately. The accuracy of system's output will also be dependent on number of right knowledge. The performance exhibits the degree of satisfaction in system's operation by means of observing the systems' speed, accuracy, etc. In general, in order to compare the results of the diagnoses generated by the system with experts' diagnosis which assumed to be as a gold standard, tables and/or graphical illustrations may be used. The impact is the influence of the system on the accuracy of the physician's diagnosis, ie the practioners who use the systems like this get better performance in obtaining accurate diagnoses $(13,24,34)$.

\section{Patient's characteristics}

This rule-based expert system program has been evaluated using patients' data obtained from the archive of Internal Medicine Department, Cerrahpasha Medical Faculty, Istanbul University, Turkey. For this evaluation of LUNG-EX-PRO, the data for 189 patients, 69 of which were female have been used.

The distribution of 189 patients' diagnoses with respect to respiratory system diseases is shown in Table 1 as the first column. During this diagnosing process, the expert physicians have used the data for each patient includes the patients' history (symptoms, and present and past medical history) and physical findings, radiological and laboratory data.
Reset
Run
Does the patient have a cough? (Yes, No) Yes.
Is the duration of cough les than three weeks? (Yes, No) Yes.
Does the patient have a fever? (Yes, No) No
Does the patient have shortness of breath? (Yes, No) No
I think your disease and our recommendation is foreign-body-in-bronchi-and-go-to-pneumolog

Figure 3: An example of operation of this program 
Table 1: Distribution of results for four data sets and gold standards with respect to lung diseases

\begin{tabular}{|c|c|c|c|c|c|}
\hline Diseases & $\begin{array}{l}\text { Diagnoses of } \\
\text { gold standarts }\end{array}$ & $\begin{array}{c}\text { Program's } \\
\text { First data } \\
\text { set }\end{array}$ & $\begin{array}{c}\text { diagnoses } \\
\begin{array}{c}\text { Second data } \\
\text { set }\end{array} \\
\end{array}$ & $\begin{array}{c}\text { for four } \\
\text { Third data } \\
\text { set }\end{array}$ & $\begin{array}{c}\text { data sets } \\
\text { Fourth data } \\
\text { set }\end{array}$ \\
\hline Pulmonary embolism & 1 & 0 & 0 & 0 & 1 \\
\hline $\begin{array}{l}\text { Pulmonary } \\
\text { hypertension }\end{array}$ & 1 & 0 & 0 & 0 & 1 \\
\hline COPD (Emphysema) & 29 & 27 & 27 & 29 & 29 \\
\hline $\begin{array}{l}\text { COPD (Chronic } \\
\text { bronchitis) }\end{array}$ & 38 & 38 & 38 & 38 & 38 \\
\hline Bronchial asthma & 26 & 29 & 29 & 27 & 27 \\
\hline Bronchiectasis & 6 & 5 & 5 & 5 & 5 \\
\hline $\begin{array}{l}\text { Upper respiratory } \\
\text { tract infection }\end{array}$ & 1 & 0 & 1 & 0 & 1 \\
\hline Sinusitis & 0 & 1 & 0 & 1 & 0 \\
\hline $\begin{array}{l}\text { Typical bacterial } \\
\text { pneumonia }\end{array}$ & 22 & 33 & 33 & 33 & 22 \\
\hline Atypical pneumonia & 11 & 0 & 0 & 0 & 11 \\
\hline Lung abscess & 1 & 0 & 1 & 0 & 1 \\
\hline Tuberculosis & 34 & 1 & 1 & 35 & 35 \\
\hline $\begin{array}{l}\text { Interstitial lung } \\
\text { disease }\end{array}$ & 2 & 1 & 1 & 1 & 1 \\
\hline Sarcoidosis & 2 & 0 & 0 & 0 & 0 \\
\hline Lung cancer & 13 & 0 & 12 & 0 & 12 \\
\hline Bronchial adenoma & 0 & 31 & 18 & 13 & 0 \\
\hline Bronchorrhea & 0 & 16 & 16 & 0 & 0 \\
\hline Cardiac failure & 1 & 3 & 3 & 3 & 3 \\
\hline Pericardial effusion & 1 & 0 & 0 & 0 & 0 \\
\hline $\begin{array}{l}\text { Other causes } \\
\text { (pneumolog) }\end{array}$ & 0 & 3 & 3 & 3 & 2 \\
\hline $\begin{array}{l}\text { Other causes } \\
\text { (cardiolog) }\end{array}$ & 0 & 1 & 1 & 1 & 0 \\
\hline $\begin{array}{l}\text { The number of } \\
\text { diagnosing errors } \\
\text { with respect to the } \\
\text { gold standart }\end{array}$ & - & 68 & 54 & 33 & 6 \\
\hline
\end{tabular}

\section{Results}

In this study, these expert physicians' diagnosis results are adopted as gold standards (see the first column of Table 1) which mean that they are taken as absolute accurate references to verify the correctness of the diagnosis generated by this program.

In order to evaluate this expert system with the hundred and eighty nine patients data, each patient's data is classified into three sub-data such as patient's history and physical findings, radiological data and laboratory data. The combination of these three subdata forms four different data sets for each patient. These data sets are

1. First data set: Patient's history and physical findings (Basic data),

2. Second data set: Basic data with radiological data,
3. Third data set: Basic data with laboratory data,

4. Fourth data set: Basic data with radiological and laboratory data.

The distribution of diagnosing results generated by the system for each data set is listed in Table 1 together with the list of gold standards. The difference between the diagnosis numbers for each disease indicates the number of misdiagnosed patients, ie the number of error for the considered disease. So, the summation of errors for whole diseases will give us two times the number of diagnosing errors occurred during the diagnosis operation for considered data set. The errors happened in these operations are given in the Table 1 as well. These comparisons with gold standards one by one are illustrated in Figure 4a-d. 


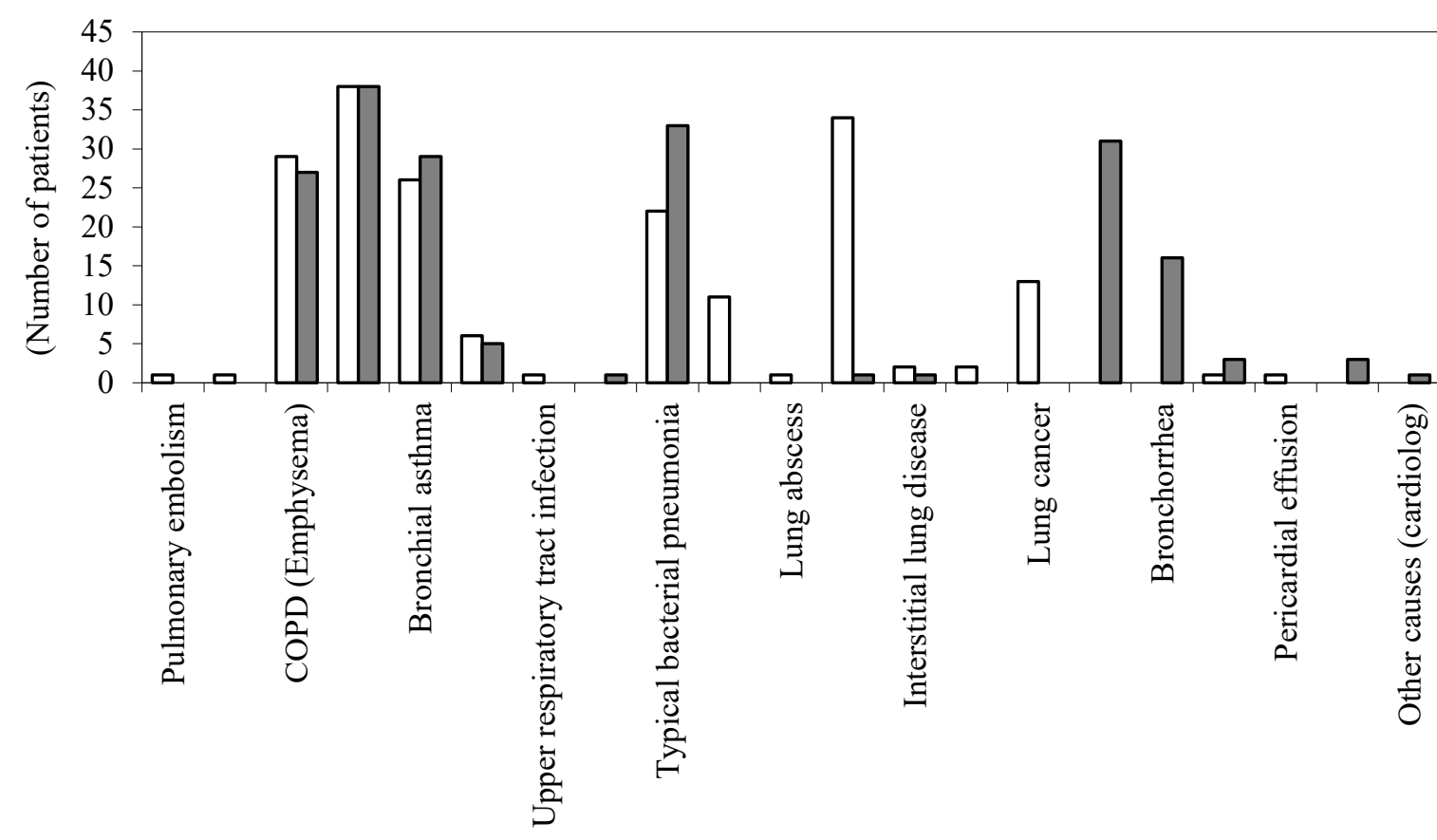

口Diagnoses of gold standarts $\quad \square$ Program' diagnosis with the first data set

Figure 4a: Comparison of the gold standards and system' results with the first data set.

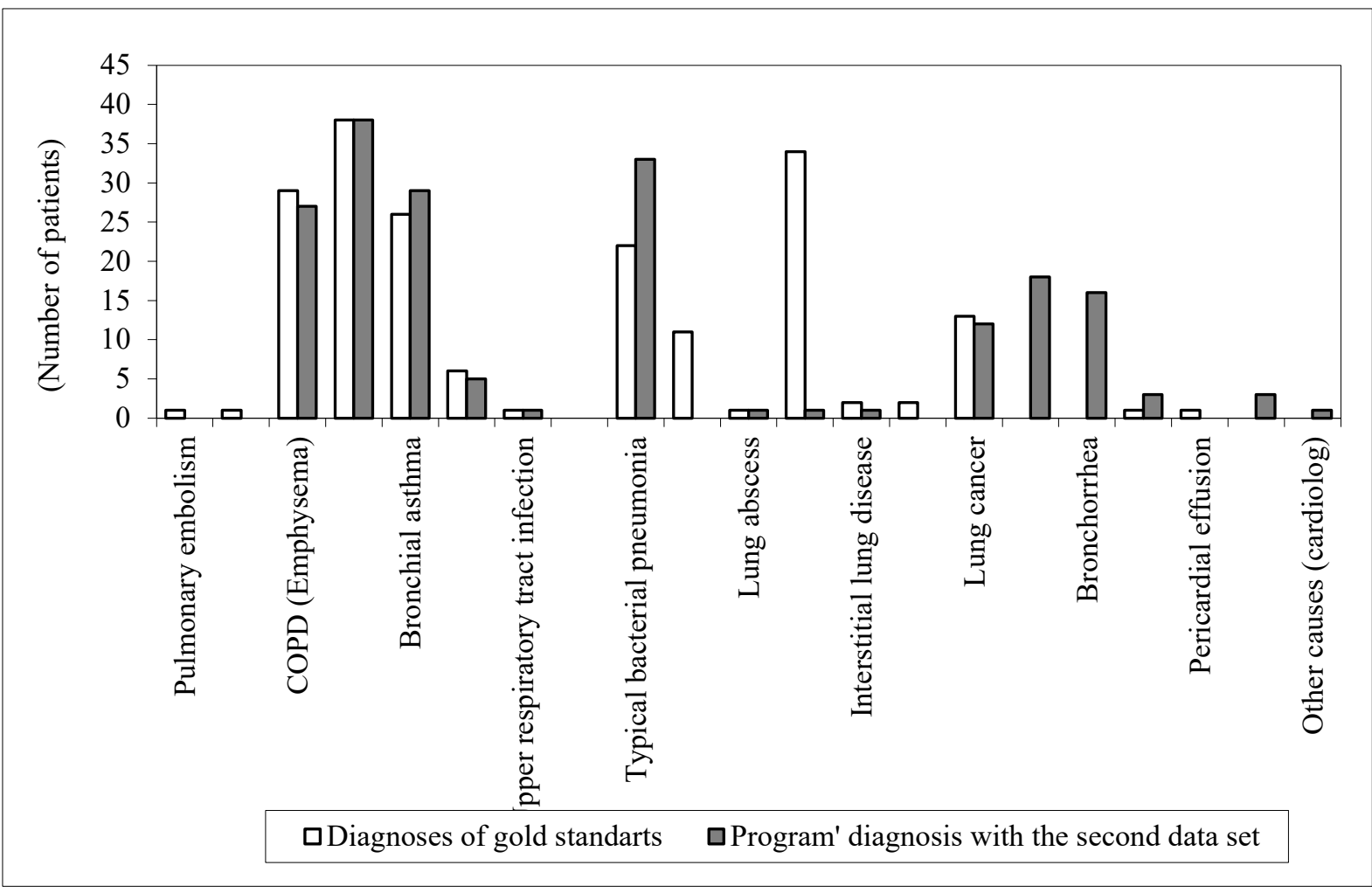

Figure 4b: Comparison of the gold standards and system' results with the second data set. 


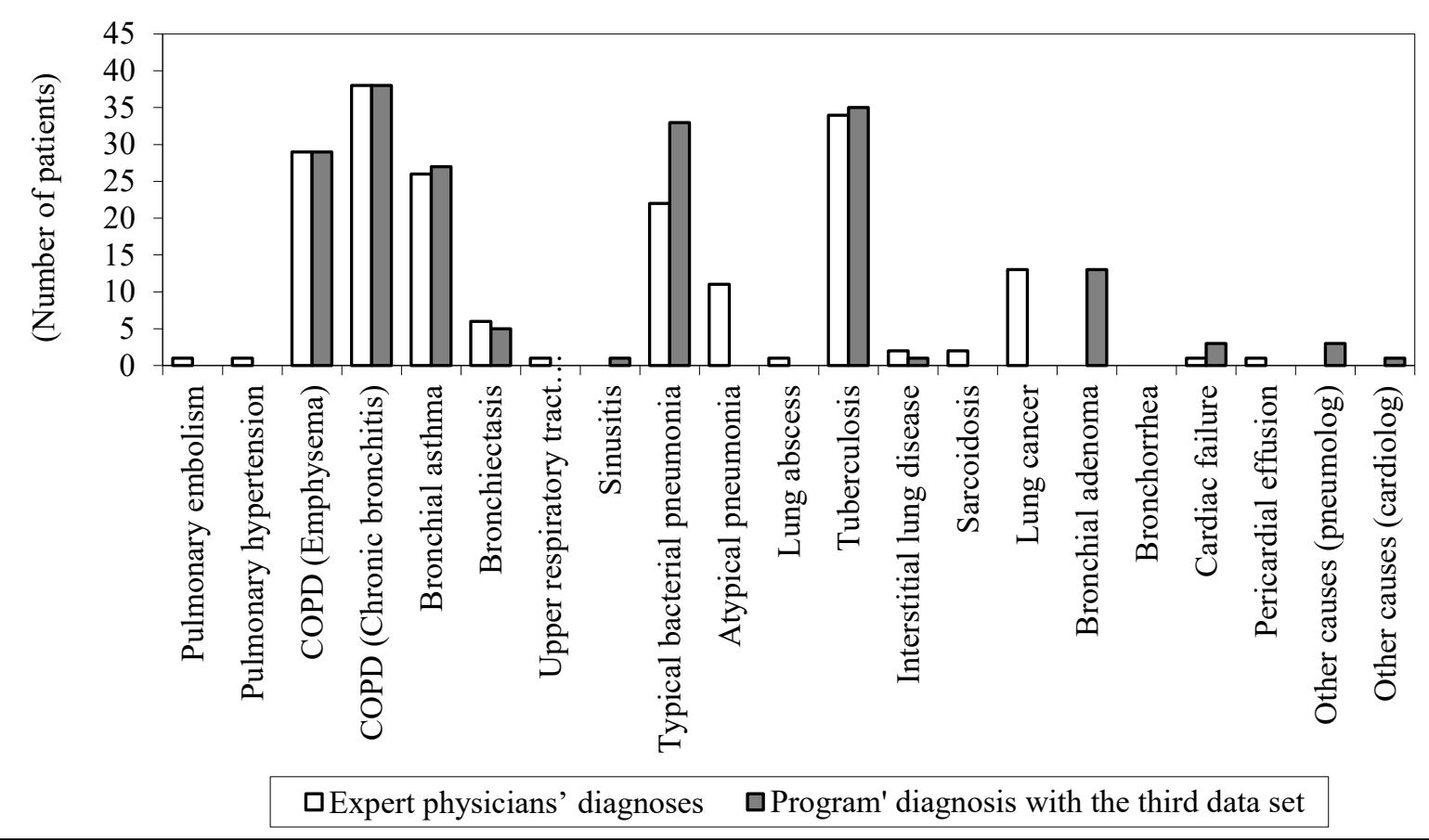

Figure 4c: Comparison of the gold standards and system' results with the third data set.

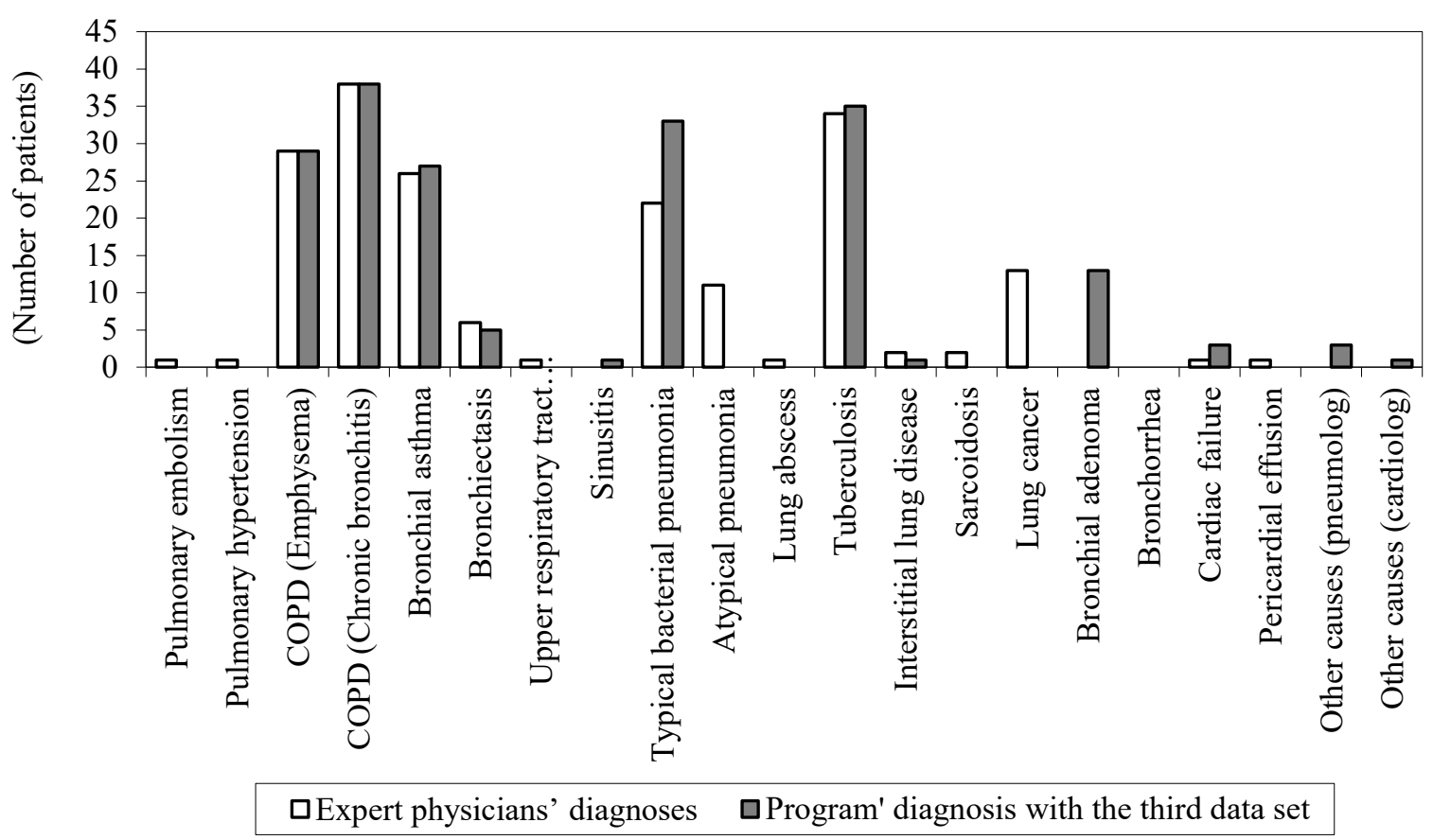

Figure 4d: Comparison of the gold standards and system' results with the fourth data set. 
Using these number of errors, percentage of accuracy may be easily calculated for each data set as shown in Figure 5.

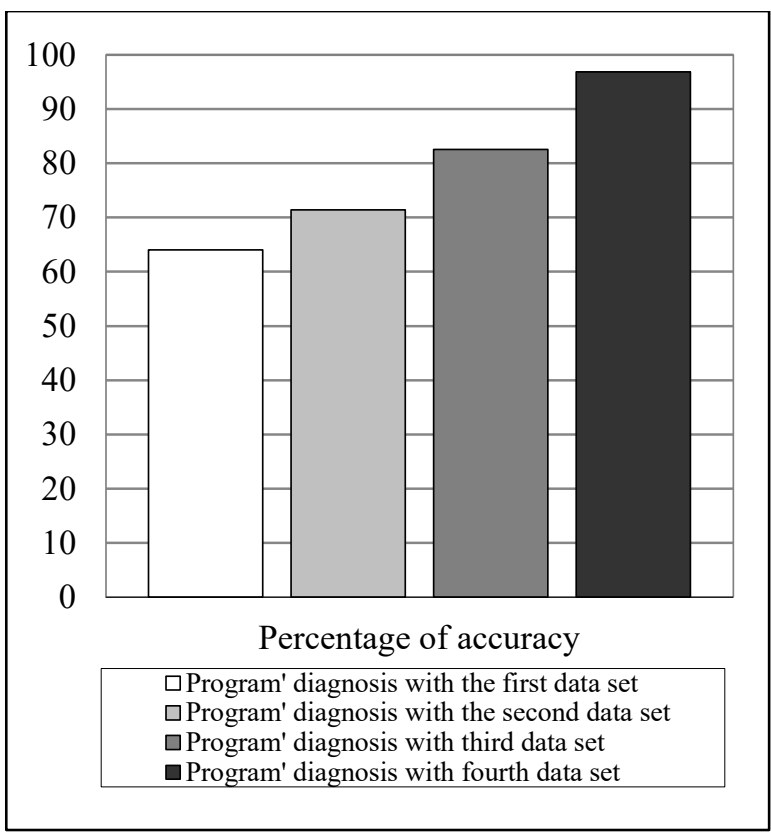

Figure 5: Accuracy rates of four data sets

\section{Discussion}

The aspects of the evaluation process explained in the earlier section, corresponds to two of three fundamental measures suggested by Wyatt. These are structure and performance which means accuracy and reliability in the data and the satisfaction and the accuracy in system operation. Looking into this study from this point, we can concluded followings :

The accuracy rates of diagnosis results for four data sets are $64.02 \%, 71.43 \%, 82.54 \%$ and $96.83 \%$, respectively as shown in the Table 2 .

The close examination of the data contents used for the first data set indicates that the data is subjective, but fundamental since without considering it in system operation diagnosing output cannot be obtained. The accuracy of this type of data is related to mostly patients' intellectual ability and cultural level. For this basic data set, this system provides diagnosis outputs with $64.02 \%$ accuracy (68 errors) for 189 patients. Adding radiological findings to the fundamental data, the accuracy of the system rises to $71.43 \%$ (error decreases 54) enhancing the system performance more than $7 \%$. If the laboratory findings are used as the additional data, the accuracy of outputs rises to $82.54 \%$ (error decreases 33 ) providing more than $18 \%$ enhancement. On the other hand, when we run the system with both additional data together, the accuracy jumps to $96.83 \%$ (error decreases 6) enhancing the system performance more than 33\% which is higher than the summation of enhancement of the both cases .

\section{Conclusion}

We can conclude that the accuracy of the system is enhanced with the increasing total amount of data for each patient. Especially additional objective and reliable data provides much better accuracy for the output of system as expected.

Finally, further improvement on the performance and accuracy of the system may be obtained by designing the program with the self-learning ability.

Moreover, the use of this kind of systems should be approved both by the patient and the physician.

Conflict of interest

There is no conflict of interest.

\section{References}

1. Barr A, Feigenbaum EA, editors. The Handbook of Artificial Intelligence. Stanford, California: Heuris Tech Press; 1982, Vol.2.

2. Fox J, Alvey P. Computer Assisted Medical Decision Making. BMJ 1983; 287: 742-746.

3. Giarratano J, Riley G, editors. Expert Systems. 2nd ed. Boston: PWS Pub Com; 1994.

4. Barnett GO. Dxplain an evolving diagnostic decision support system. JAMA 1987; 258: 67-71.

5. Compton P, Jansen R. Diabetes expert systems: planning for long term use. Hormone and Metabolic Research Supplement Series 1990; 24: 124-129.

6. Forsstrom J, Nuutila P, Irjala K. Using the ID3 algorithm to find discrepant diagnoses from laboratory databases of thyroid patients. Medical Decision Making 1991; 11: 171175 .

7. Verdaguer A. Validation of the Medical Expert System PNEUMON-IA. Computers and Biomedical Research 1992; 25: 511-526.

8. Hernandez C. Validation of the medical expert system RENOIR. Computers and Biomedical Research 1994; 27 : 456-471.

9. Birndorf NJ. An expert system to diagnose anemia and report results directly on hematology forms. Computers and Biomedical Research 1996; 29: 16-26.

10. Thornett AM. Computer decision support systems in general practice. International Journal of Information Management 2001; 21: 39-47.

11. Zini G. Artificial intelligence in hematology. Hematology 2005; 10(5): 393-400

12. Schectman JM, Schorling JB, Nadkarni MM, Voss JD. Determinants of physician use of an ambulatory prescription expert system. International Journal of Medical Informatics 2005;74: 711-717.

13. Razzouk D, Mari JJ, Shirakawa I, Wainer J, Sigulem D. Decision support systems for the diagnosis of schizophrenic disorders. Brazilian journal of Biology Research 2006; 39 (1): 119-128. 
14. Naser SSA, Ola AZA. An expert system for diagnosing eye diseases using CLIPS. Journal of Theoretical and Applied Information Technology 2008; 4(10):923-930.

15. Naser SSA, Dahdooh RA, Mushtaha A, Naffar ME. Knowledge management in ESMDA: expert system for medical diagnostic assistance. ICGST- AIML Journal 2010 Oct; 10(1):31-40.

16. Naser SSA, Hissi HE, Rass MA, Khozondar NE. An expert system for endocrine diagnostic and treatments using JESS Journal of Artificial Intelligence 2010; 3(4):239-251.

17. Winstanley T, Courvalin P. Expert systems in clinical microbiology. Clinical Microbiology Reviews 2011 July; 24(3); 515-556.

18. Nohria R. Medical expert system-A comprehensive review. International Journal of Computer Applications 2015 Nov; 130(7): 44-50.

19. Bahrami A, Roozitalab N, Jafari S, Bahrami A. An expert system for diagnosing dilated cardiomyopathy. International Journal of Engineering Science Invention 2014 Mar; $3(3): 38-42$.

20. Singla J, Grover D, Bhandari A. Medical expert systems for diagnosis of various diseases. International Journal of Computer Applications 2014 Mar; 93(7): 36-43.

21. Bergman DA, Pantell RH. The art and science of medical decision making. Journal of Pediatrics 1984; 104 (5): 649 656.

22. Elstein AS, Bordage G. Psychology of clinical reasoning In: Dowie J, Elstein AS, editors. Professional Judgement a reader in clinical decision making. 6th ed. Cambridge: Cambridge University Press; 1999. P. 109-130.

23. Elstein AS, Friedman CP, Wolf FM, Murphy G, Miller J, Fine $\mathrm{P}$, et al. Effects of a decision support system on the diagnostic accuracy of users: A preliminary report. Journa of The American Medical Informatics Association 1996; 3 (6): 422-428.

24. File PE, Dugard PI, Houston AS. Evaluation of the use of induction in the development of a medical expert system. Computers and Biomedical Research 1994; 27: 383-395.
25. Hunt DL, Haynes RB, Hanna SE. Effects of Computerbased clinical decision support systems on physician performance and patient outcomes, A systematic review. JAMA 1998; 280: 1339-1346.

26. Pankaskie MC, Wagner MM. Use of CLIPS for representation and inference in a clinical event monitor. In: Masys DR, editor. Proc AMIA Annu Fall Symp 1997. Proceedings of American Medical Informatics Association Annual Fall Symposium; 1997 Oct 25-29; Nashville, Tennessee, United States of America. Oxford; 1997. P. 1937.

27. Camilli A. Hemoptysis. In: Greene HL, et. al, editors. Decision Making in Medicine An Algorithmic Approach. 2nd ed. St. Louis: Mosby; 1998. P. 388-389.

28. Camilli A. Pulmonary Dyspnea. In: Greene HL, et. al, editors. Decision Making in Medicine An Algorithmic Approach. 2nd ed. St. Louis: Mosby; 1998. P.396-397.

29. Clements NC. Wheezing. In: Greene HL, et. al, editors. Decision Making in Medicine An Algorithmic Approach. 2nd ed. St. Louis: Mosby; 1998. P. 392-393.

30. Drazen JM, Weinberger SE. Disorders of the respiratory system. In: Fauci AS, et al, editors. Harrison's Principles of Internal Medicine. 14th ed. New York: McGraw-Hill; 1998. P. 1407-1493.

31. Knoper SR. Cough. In: Greene HL, et. al, editors. Decision Making in Medicine An Algorithmic Approach. 2nd ed. St. Louis: Mosby; 1998. P. 388-389.

32. Murray JF. Respiratory Diseases. In: Wyngaarden JB, et al, editors. Cecil Textbook of Medicine. 19th ed. Philadelphia: W.B. Saunders Company; 1992. P. 369-458.

33. Stauffer JL. Lung. In: Tierney LM, et. Al, editors. Current Medical Diagnosis and Treatment. 36th ed. Stamford: Appleton \& Lange; 1997. P. 236-319.

34. Wyatt J. Quantitative evaluation of clinical software, exemplified by decision support systems. International Journal of Medical Informatics 1997; 47: 165-173.

Copyright (C) 2016 The Author(s); This is an open-access article distributed under the terms of the Creative Commons Attribution License (http://creativecommons.org/licenses/by/4.0), which permits unrestricted use, distribution, and reproduction in any medium, provided the original work is properly cited. All Rights reserved by international journal of Medical Science and Discovery. 